\title{
REVISTA PRÁTICAS EM GESTÃO PÚBLICA UNIVERSITÁRIA - ERA SÓ O QUE FALTAVA
}

Ivaneide Nunes Grizente ${ }^{1}$; Regina Macedo Dantas²

\section{Como citar:}

GRIZENTE, I. N.; DANTAS, R. M. Revista práticas em gestão pública universitária - era só o que faltava. In: ABEC MEETING, 1, 2017, Curitiba. Anais... Curitiba: Associação Brasileira de Editores Científicos, 2017. p. $32-36$.

http://dx.doi.org/10.21452/abecmeeting.2017.006

Resumo: Este trabalho tem como objetivo apresentar sob o viés histórico, a Revista Práticas em Gestão Pública Universitária/PGPU da UFRJ, publicação eletrônica de caráter interdisciplinar. Serão descritas suas finalidades e expectativas, que frente à inicial necessidade de veiculação da produção científica dos técnicos administrativos, nasce com a finalidade de divulgar as produções científicas dos servidores (docentes e técnico administrativos) e discentes de pós-graduação de instituições públicas de nível superior brasileiras. O Trabalho é metodologicamente qualitativo, cujos métodos são documental e bibliográfico. Com isso foi apresentada a história da Revista PGPU iniciada no ano de 2015, que tem a expectativa de estimular o intercâmbio de ideias; contribuir para a produção e socialização do conhecimento; encorajar a formação de uma comunidade nacional de interessados no debate sobre a Gestão Pública Universitária entre outros.

Palavras-Chave: Revista Eletrônica. Práticas em Gestão Pública. Técnicos administrativos.

Abstract: This paper aims to present, under the historical bias, the Journal of Practices in Public Management University / PGPU of UFRJ, electronic publication of an interdisciplinary nature. Its aims and expectations will be described, given the initial need to disseminate the scientific production of administrative technicians, it was born with the purpose of disseminating the scientific productions of the servants (teachers and administrative technicians) and postgraduate students of public higher education institutions Brazilians. The work is methodologically qualitative, whose methods are documentary and bibliographical. With this was presented the history of the PGPU Magazine started in the year 2015, which is expected to stimulate the exchange of ideas; contribute to the production and socialization of knowledge; encourage the formation of a national community of stakeholders in the debate on University Public Management among others.

Keywords: Electronic Journal. Practices in Public Management. Technical administrative.

\section{INTRODUÇÃO}

Atualmente, vive-se sob o paradigma da sociedade da informação e do conhecimento, e se as informações constituem a base do conhecimento, a aquisição deste, supõe o desencadear de uma série de ações no tocante as informações apreendidas, e principalmente, o que fazer com elas.

Nesse cenário, impõe-se também a revolução tecnológica, e nesse sentido, o que a caracteriza não é apenas a informação ou conhecimento, mas o aproveitamento deste conhecimento e processamento da informação/comunicação, em um círculo de retroalimentação acumulativa entre a inovação e sua utilidade para o mundo. (CASTELLS, 2003)

Nesse sentido, e através do levantamento de dados realizado no ano de 2015, referentes à formação/qualificação do quadro técnico-administrativo da Universidade Federal do Rio de Janeiro (UFRJ), a Pró-Reitoria de Pessoal (PR-4) observou uma lacuna quanto a 
produção e divulgação das experiências dos técnicos administrativos em educação (TAEs). Tal levantamento assegurou que um número considerável dos técnico-administrativos produzem trabalhos acadêmicos, porém não encontram um espaço para o escoamento dessa produção, uma vez que historicamente, os espaços destinados às publicações acadêmicas tendem a acolher a produção de docentes e pós graduados.

É assim que nasce a revista Práticas em Gestão Pública Universitária (PGPU), periódico eletrônico semestral que tem como principal propósito, divulgar a produção científica dos diferentes categorias das universidades públicas (técnico-administrativos, docentes e alunos de pós-graduação). Trata-se de periódico que contempla a publicação de análises, reflexões e resultados de trabalhos voltados para a área da Gestão Pública Universitária de técnico administrativos e docentes (ativos e aposentados), além de discentes de instituições públicas de ensino superior de todo o país, priorizando a publicação de trabalhos escritos por técnicos administrativos ou que contenham técnicos entre seus autores.

Diante disso, o objetivo desse trabalho é historicizar a Revista PGPU, descortinando desde sua criação às expectativas. Quanto à metodologia, é um trabalho de natureza qualitativa, pois segundo Minayo (2007 p.57) “ Método qualitativo é o que se aplica ao estudo da história, das relações, das representações, das crenças, das percepções e das opiniões, produtos das interpretações que os humanos fazem a respeito de como vivem", o que vem ao encontro do que se pretende nesse trabalho.

Ainda quanto ao método, foram realizadas articulações de fontes documental e bibliográfica. Documental porque foram consultados documentos em órgão público quando do levantamento sobre a capacitação/qualificação dos servidores da UFRJ; bibliográfica, porque, conforme afirma Gil (2002 p. 44): “A pesquisa bibliográfica é desenvolvida com base em material já elaborado, constituído principalmente de livros e artigos científicos. [...]”.

\section{A REVISTA PGPU}

Pormenorizando sua criação, a revista foi concebida com o estudo realizado por um servidor técnico-administrativo, Gustavo Cravo, a partir do diagnóstico de uma necessidade iminente baseada no perfil de qualificação do corpo de servidores pertencentes a categoria técnico-administrativa, além disso, utilizando como escopo fundamental o Documento de Área Interdisciplinar da Coordenação de Aperfeiçoamento de Pessoal de Nível Superior/CAPES e as informações sobre o Qualis Periódico/CAPES (BARATA, 2016). Segue planilha de atividades. 
Quadro 1 - Resumo das principais ações da Revista PGPU.

\begin{tabular}{|c|c|c|}
\hline Ano & Iniciativa & Providencia \\
\hline \multirow[t]{3}{*}{2015} & $\begin{array}{l}\text { Concepção da Revista pelos } \\
\text { idealizadores } \\
\text { administrativos }\end{array}$ & $\begin{array}{l}\text { Marcar reunião coma Pro-Reitora de } \\
\text { Pessoal e a Coordenação de Políticas } \\
\text { de Pessoal. }\end{array}$ \\
\hline & Reunião realizada & $\begin{array}{l}\text { Solicitar servidores que atuam em } \\
\text { outras áreas mas que detém } \\
\text { conhecimento e expertise no assunto } \\
\text { para integrar a equipe da Revista. }\end{array}$ \\
\hline & $\begin{array}{l}\text { Definição dos critérios e } \\
\text { análise da NBR } 6023 / 2000- \\
\text { da Associação Brasileira de } \\
\text { Normas técnicas-ABNT. }\end{array}$ & $\begin{array}{l}\text { Análise minuciosa da parte legal e } \\
\text { estrutural da uma revista eletrônica } \\
\text { junto aos órgãos de controle, } \\
\text { considerando as exigências da } \\
\text { CAPES. }\end{array}$ \\
\hline \multirow[t]{5}{*}{2016} & $\begin{array}{l}\text { Elaborar Projeto e escopo da } \\
\text { Revista para apresentação } \\
\text { para a Gestão PR/4 }\end{array}$ & $\begin{array}{l}\text { Apresentação do escopo da Revista } \\
\text { para a Pro-Reitora de Pessoal e sua } \\
\text { equipe. }\end{array}$ \\
\hline & $\begin{array}{l}\text { Elaborar a estrutura da } \\
\text { revista quanto à prazos e } \\
\text { seções temáticas }\end{array}$ & $\begin{array}{l}\text { Pesquisa junto ao portal CAPES } \\
\text { quanto as demandas necessárias para } \\
\text { Qualis. }\end{array}$ \\
\hline & $\begin{array}{l}\text { Elaborar o Projeto no } \\
\text { formato de apresentação para } \\
\text { evento de Gestão de Pessoas }\end{array}$ & $\begin{array}{l}\text { Apresentação do Projeto da Revista } \\
\text { no Encontro Nacional de Dirigentes } \\
\text { de Pessoal-ENDP/Porto Alegre RS }\end{array}$ \\
\hline & $\begin{array}{l}\text { Escolha e convite editores } \\
\text { chefe e associados }\end{array}$ & Divulgação dos editores \\
\hline & $\begin{array}{lll}\text { Escolha e convite } & \text { dos } \\
\text { Avaliadores } & & \\
\end{array}$ & Divulgação dos avaliadores \\
\hline \multirow[t]{6}{*}{2017} & $\begin{array}{l}\text { Recepção } \quad \text { dos } \\
\text { artigos/entrevistas/vivencias }\end{array}$ & $\begin{array}{l}\text { Edição/avaliação dos artigos, } \\
\text { entrevistas, vivencias. }\end{array}$ \\
\hline & Lançamento da Revista & Publicação dos artigos \\
\hline & $\begin{array}{l}\text { Preencher } \\
\text { sormulário de } \\
\text { solicitação de International } \\
\text { Standard Serial Number- } \\
\text { ISSN }\end{array}$ & $\begin{array}{l}\text { Solicitar ISSN junto ao Instituto } \\
\text { Brasileiro de Informação em Ciência } \\
\text { e Tecnologia (IBICT) }\end{array}$ \\
\hline & $\begin{array}{l}\text { Reunião do } \\
\text { editorial }\end{array}$ & $\begin{array}{l}\text { Participação do corpo editorial da } \\
\text { PGPU nas reuniões do Observatório } \\
\text { de Periódicos da UFRJ. }\end{array}$ \\
\hline & Recepção do ISSN & $\mathrm{n}^{0} 2526-8503$ \\
\hline & $\begin{array}{l}\text { Recepção contínua de } \\
\text { artigos, resenhas, entrevistas } \\
\text { e vivências }\end{array}$ & $\begin{array}{l}\text { Edição, submissão } \\
\text { acompanhamento de avaliação dos } \\
\text { artigos junto aos avaliadores, bem } \\
\text { como feed-back aos escritores. }\end{array}$ \\
\hline
\end{tabular}

Fonte: Elaborado pelas autoras com base na agenda PGPU/UFRJ.

O lançamento da revista se deu no dia 29 de maio de 2017 (propositalmente no mês identificado como o do trabalhador), em evento no qual estiveram presentes autoridades da UFRJ (Reitor e Pró-reitor de Pessoal), a equipe de editores e representantes das categorias envolvidas: ADUFRJ (Associação dos Docente da UFRJ), SINTUFRJ (Sindicato dos Trabalhadores em Educação da UFRJ), APG (Associação dos Pós-graduandos) e SINTTUFRJ (Sindicato dos Terceirizados da UFRJ), conforme noticiou o Jornal do SINTUFRJ: "Revista Eletrônica mostra a produção intelectual da categoria na UFRJ. 
Publicação lançada pela PR-4, é aberta a todos os segmentos da Universidade, incluindo os trabalhadores terceirizados, e a outras instituições públicas de ensino superior." (JORNAL SINTUFRJ, 2017.

Com isso, a PGPU visa estimular o intercâmbio de ideias entre o corpo técnicoadministrativo em educação, docentes e discentes de instituições públicas de ensino superior e os terceirizados dessa instituições; contribuir para a produção e socialização do conhecimento sobre Gestão Pública Universitária e suas subáreas ; encorajar a formação de uma comunidade nacional de interessados no debate sobre a Gestão Pública Universitária ; contribuir para a produção e socialização do conhecimento sobre Gestão Pública Universitária e suas subáreas; encorajar a formação de uma comunidade nacional de interessados no debate sobre a Gestão Pública Universitária.

A Revista publicou seu primeiro número em maio de 2017, com um total de 09 artigos, e todos assinados exclusivamente ou em co-autoria com técnico-administrativos, oriundos de Instituições Ensino Superior como Instituto Federal Rio Janeiro-IFRJ, Universidade Estado de São Paulo-UNESP, Universidade Federal Minas Gerais-UFMG, Universidade Federal da Fronteira Sul-UFFS, Universidade Federal Rio Janeiro-UFRJ, Universidade Federal Fluminense-UFF, Centro Federal de Educação Tecnológica do Rio de Janeiro-CEFET/RJ.

O primeiro número publicou ainda um Relato de Experiência, uma Entrevista, um relato de Vivências em Gestão e uma Resenha. Na seção entrevista, foi publicada a de uma servidora técnica administrativa e conforme editorial- PGPU, Regina Dantas escreveu:

Gildélia Maria de Oliveira (conhecida carinhosamente por Gil) em comemoração aos seus trinta anos de UFRJ. A Gil é uma daquelas servidoras que faz parte do "patrimônio" da Universidade, não somente pela dedicação de anos em um mesmo lugar, a PR-4, mas por representar aqueles que carregam consigo o conhecimento e que merecem esta singela homenagem. (PGPU, 2017)

No intuito de concluir o presente trabalho, podermos garantir que a PGPU cumpriu com seu objetivo e vem consolidando uma ação inédita na UFRJ de mesclar diferentes áreas do conhecimento abarcando distintas categorias. Dessa forma, o periódico está proporcionando oportunidade de apresentação e troca de experiências entre pesquisadores em nível nacional.

\section{REFERÊNCIAS}

ASSOCIAÇÃO BRASILEIRA DE NORMAS TÉCNICAS-ABNT. NBR 6023/2002. Informação e documentação - Referências - Elaboração. Rio de Janeiro, 2002. 24 
BARATA, R. de C.B. Dez coisas que vc deveria saber sobre o Qualis. In: Revista Brasileira de Pós-graduação/RBPG, Brasília: CAPES, v. 13, n. 30, p. 013-040, Jan/Abr. 2016.

CASTELLS, M.. A Galáxia da Internet: Reflexões sobre a Internet, os negócios e a sociedade. Rio de Janeiro: Jorge Zahar Editor, 2003.

GIL, A.C. Como elaborar projetos de pesquisa - 4. ed. - São Paulo : Atlas, 2002

MINAYO, M. C. S. O desafio do conhecimento, pesquisa qualitativa em saúde. 10 ed. São Paulo: Hucitec, 2007.

SINTUFRJ. Jornal do Sindicato dos Trabalhadores da UFRJ/SINTUFRJ - edição $\mathrm{n}^{0}$ 1204, 5 a 1 de junho de 2017. Disponível em: www.sintufrj.urg.br)). 